\title{
O professor e suas ações educativas no processo de alfabetização científica e tecnológica no ensino de ciências nos anos iniciais do ensino fundamental
}

Hanslivian Correia Cruz Bonfim hansbonfim@hotmail.com

0000-0002-7833-871X

Secretaria Municipal de Educação do Município de Curitiba

Orliney Maciel Guimarães orliney@quimica.ufpr.br 0000-0003-4762-4884

\begin{abstract}
RESUMO
O objetivo dessa pesquisa foi o de analisar as ações educativas desenvolvidas pelos professores que lecionam Ciências no Ciclo II do Ensino Fundamental de Curitiba, a fim de identificar se tais ações contribuem para o processo de alfabetização científica e tecnológica (ACT) dos estudantes. O presente trabalho é um recorte de uma pesquisa de mestrado, com abordagem qualitativa, e cujos dados foram constituídos mediante entrevistas com nove professores, observações de aulas, análise das diretrizes curriculares para a Educação Municipal de Curitiba e dos planos de aula dos professores. Foi utilizada a Análise Textual Discursiva de Moraes e Galiazzi (2011), para análise dos dados. Nesse artigo são discutidas duas categorias de análise: Recursos didáticos e Estratégias de Ensino. Com o estudo foi possível identificar que os professores utilizam em suas aulas diferentes recursos didáticos e estratégias de ensino, o que se considera relevante para o processo de ACT.
\end{abstract}

PALAVRAS-CHAVE: Alfabetização científica e tecnológica. Anos iniciais. Ensino de ciências 


\section{INTRODUÇÃO}

A criança forma sua visão de mundo e constrói suas próprias explicações sobre o funcionamento dos fenômenos naturais e sociais, por meio da interação que estabelece com adultos, crianças, objetos, espaços, artefatos tecnológicos, etc., enfim, com tudo o que compõe seu espaço social e cultural. Sendo assim, ao ingressar na escola o estudante já possui vários conhecimentos prévios sobre o mundo no qual está inserido. E cabe à escola considerar estes conhecimentos, mas, também, ampliá-los, aproximando-os dos conhecimentos científicos e tecnológicos, para que o estudante tenha a habilidade de explicar o mundo mediante a linguagem científica.

Para que o Ensino de Ciências contribua para o processo de Alfabetização Científica e Tecnológica (ACT) dos estudantes, e que estes possam por meio da linguagem científica participar de forma mais ativa na sociedade, tomando decisões, questionando, opinando, é necessário que o ensino dos conteúdos de Ciências esteja articulado com questões reais, as quais os estudantes vivenciam em seu cotidiano. Portanto, é importante que o professor estabeleça relações entre o que o estudante conhece e o que a escola apresenta de conhecimento novo, ampliando dessa forma seu conhecimento.

O papel do professor é essencial para o desenvolvimento da ACT, a fim de planejar as ações educativas voltadas para esse propósito. Contribuindo para que o estudante faça relações dos conteúdos aprendidos na escola com questões de seu cotidiano, e para que tome decisões no seu contexto social.

Sendo assim, o presente trabalho tem como objetivo analisar as ações educativas, as realizadas pelos professores dos anos iniciais do Ensino Fundamental da rede municipal Curitiba, os quais lecionam Ciências Naturais, a fim de identificar se tais ações contribuem para o processo de ACT dos estudantes. Neste artigo ressaltam-se as ações educativas, que são compreendidas como os meios pelos quais os professores utilizam para atingir os objetivos de aprendizagem de seus estudantes, isto é, as estratégias e recursos didáticos que planejam e organizam para o desenvolvimento das aulas. Assim, as discussões desse trabalho estão voltadas para os recursos didáticos e estratégias de ensino utilizadas pelos professores atuantes no ensino de Ciências Naturais no Ciclo II.

O artigo é um recorte de uma dissertação de mestrado, e serão discutidos os seguintes temas: Alfabetização científica e tecnológica nos anos iniciais do ensino fundamental; O professor e suas ações educativas no processo de ACT; Metodologia da pesquisa e Discussão dos resultados.

\section{ALFABETIZAÇÃO CIENTÍFICA E TECNOLÓGICA NOS ANOS INICIAIS DO ENSINO FUNDAMENTAL}

A educação formal tem como papel o de habilitar o estudante a compreender a realidade na qual está inserido, tanto os aspectos sociais, como os naturais, de forma que com esse conhecimento ele possa agir na sociedade de forma crítica e consciente, que possa participar dos debates e decisões que estão na sociedade (CRUZ; ZYLBERSZTAJN, 2001). Portanto, essa perspectiva de educação está baseada em "argumentos para a promoção da alfabetização 
científica para a população em geral, o que fornece uma base nacional para que o Ensino de Ciências se torne tão relevante quanto possível para um público tão amplo possível" (CRUZ; ZYLBERSZTAJN, 2001, p. 170).

Os referidos autores, portanto, consideram que alfabetizar cientificamente, é possibilitar que as pessoas tenham acesso ao conhecimento científico e que por meio deste, possam compreender o meio no qual se encontram inseridas e agirem de forma crítica no contexto social.

Hazen e Trefil (1995, p.12) destacam que alfabetização científica "é ter o conhecimento necessário para entender os debates públicos sobre as questões de ciência e tecnologia. Ou seja: é um misto de fatos, vocabulário, conceitos, história e filosofia." E complementam que uma pessoa alfabetizada cientificamente é aquela que é capaz de entender uma notícia de jornal de cunho científico, isto é, "quando consegue lidar com as informações do campo científico da mesma forma como lida com outro assunto qualquer." (HAZEN; TREFIL, 1995, p. 12). Os autores destacam que não é necessário que as pessoas sejam cientistas (façam ciência), mas que saibam usar a ciência na sua vida.

Para Roden e Ward (2010, p. 17) a "[...] população votante precisa de um entendimento da ciência para que tome decisões informadas" sobre as questões que envolvem ciência na sociedade:

[...] como, por exemplo, sementes geneticamente modificadas, aquecimento global, etc. Ainda mais importante, talvez, as unidades "familiares" individuais dever ser capazes de tirar sentido e compreender evidências relacionadas a questões médicas, como vacinação e as possíveis conexões com a saúde e com a deficiência, bem como outras escolhas de vida relacionadas com a dieta e com o lazer. (RODEN; WARD, 2010, p. $17-$ 18).

Na sociedade, observa-se como a Ciência e a Tecnologia influenciam o modo de viver das pessoas, o quanto estas tem que se adaptarem e compreenderem os avanços científicos e tecnológicos presentes no dia-a-dia. Nesse sentido, Lorenzetti (2000) ressalta que o "conhecimento científico afeta todos os aspectos da vida do indivíduo e que diariamente observa-se o seu domínio crescendo grandemente e, muitas vezes, assustadoramente." (LORENZETTI, 2000, p. 34).

Nesse sentido, não há como ficar alheios a esta situação, e a escola como instituição responsável pela educação formal, tem que contribuir, mediante o ensino de ciências, para desenvolver a ACT dos estudantes. A fim de que estes conheçam a realidade social e natural na qual estão inseridos, colaborando para a formação para a cidadania.

Vários autores consideram importante que nos anos iniciais as crianças desenvolvam o processo de ACT (LORENZETTI, 2000; SASSERON, 2008; SASSERON; CARVALHO, 2008; FABRI, 2012, VIECHINESKI, LORENZETTI, CARLETTO, 2012; VIECHINESKI, 2013, ABIB, 2013) por meio do ensino de Ciências no contexto escolar.

Nesta perspectiva os professores que atuam nesta etapa de ensino, mediante suas ações educativas, devem contribuir para que as crianças desde os anos iniciais tenham acesso aos conhecimentos voltados a Ciências Naturais, sendo que uma das metas desse ensino é o processo de ACT, de acordo com Lorenzetti (2000). Segundo este autor alfabetização científica nos anos iniciais 
pode ser definida como: "[...] um processo pelo qual a linguagem das Ciências Naturais adquire significado, constituindo-se em um meio para o individuo ampliar o seu universo de conhecimentos, a sua cultura como cidadão inserido na sociedade." (LORENZETTI, 2000, p. 122)

Assim, o ensino de Ciências deve contribuir para que o estudante desenvolva uma visão mais ampla do seu contexto social, compreendendo as relações existentes entre ciência, tecnologia e sociedade. E também possibilitar que ele perceba que os conteúdos que estão sendo ensinados na escola fazem parte de sua vida diária. Dessa forma, o ensino de Ciências contribui para a formação para a cidadania, no sentido de instrumentalizar estudantes para que compreendam melhor o seu meio natural e social, e que possam tomar decisões mais adequadas no seu contexto de vida. Portanto, o papel do professor é fundamental, pois é ele que organizará as suas ações educativas tendo como meta a ACT. Sendo assim, no próximo tópico será discutido sobre o papel do professor e suas as ações educativas no ensino de Ciências.

\section{O PROFESSOR E SUAS AÇÕES EDUCATIVAS NO PROCESSO DE ACT}

O professor possui um papel fundamental no Ensino de Ciências, para que planeje aulas mobilizadoras de aprendizagem. Neste sentido é necessário que ele compreenda como o estudante aprende a fim de poder planejar estratégias de ensino voltadas para a construção do seu conhecimento. Portanto, é necessário que haja mudanças nas formas de se ensinar Ciências nos anos iniciais, para que de fato, esta área do conhecimento contribua para a alfabetização científica e tecnológica dos estudantes.

Nesta perspectiva há algumas ações educativas que se consideram fundamentais no processo de Ensino de Ciências, para que realmente ocorra a mobilização para a aprendizagem, visando a ACT. As ações educativas que são referidas nesse trabalho se caracterizam pelos meios que os professores se utilizam para atingir os objetivos de aprendizagem, isto é, as estratégias de ensino que planejam, bem como a seleção do material didático para o desenvolvimento das aulas de Ciências. Compreendendo que as estratégias de ensino podem ser consideradas "[...] as atividades para a obtenção dos resultados pretendidos que devem ser aquilo que se estabeleceu como objetivos a alcançar" (INFORSATO; SANTOS, 2011, p. 93).

Considera-se o material didático como "[...] indispensável no processo educativo e que seu papel fundamental é contribuir para uma apropriação crítica do conhecimento por parte do aluno" (BORGES, 2012, p. 144).

A função mediadora do professor é de extrema relevância no processo educativo, pois é ele que direcionará o papel do material didático nos processos ensino-aprendizagem do conhecimento científico. Assim, a maneira como o material didático é selecionado e utilizado em sala de aula nas situações educativas determinará a direção do processo educativo, "até porque a própria educação escolar deve ter um sentido e uma direção" (BORGES, 2012, p. 144).

Sendo assim, ao selecionar e utilizar os materiais didáticos nas estratégias educativas, o professor precisa saber que direção pretende seguir em relação as suas aulas, e essa escolha se dará por meio de suas concepções referentes à Ciência, à sociedade e à educação. 
Atualmente, verifica-se uma grande quantidade de materiais didáticos disponíveis para a prática pedagógica nos anos iniciais, e esta lista de materiais pode incluir desde equipamentos sofisticados, bem como materiais simples desenvolvidos pelo próprio professor. É importante que o professor selecione diferentes materiais didáticos para organizar suas estratégias de ensino, a fim de contribuir para a aprendizagem dos estudantes. Contudo, somente os materiais didáticos não darão conta de uma efetiva aprendizagem, é necessário, portanto, que o aluno seja "desafiado e orientado para fazer da utilização um momento de conhecimento" (BORGES, 2012, p. 146). Assim, é papel do professor problematizar o seu uso e orientar os estudantes a buscarem as informações.

Destacam-se algumas estratégias educativas e alguns recursos didáticos que podem ser utilizados no Ensino de Ciências. As estratégias de ensino destacadas nessa pesquisa são: leitura de diferentes gêneros textuais, o teatro, as rodas de conversa, as atividades de campo, as feiras de Ciências e as atividades experimentais. E os recursos didáticos que se consideram importantes de serem selecionados pelo professor, ao organizar as atividades propostas são: os vídeos educativos, o jogo didático e o computador.

A primeira estratégia educativa importante para o Ensino de Ciências é a leitura de diferentes gêneros textuais, os quais são considerados "entidades sócio-discursivas e formas de ação social incontornáveis em qualquer situação comunicativa" e "caracterizam-se como eventos textuais altamente maleáveis, dinâmicos e plásticos. Surgem emparelhados a necessidades e atividades socioculturais bem como na relação com inovações tecnológicas [...]" (MARCUSCHI, 2002, p. 19). Sendo assim, com os avanços tecnológicos, dos meios de comunicação, novos gêneros são criados ou modificados, a partir da própria necessidade social. De acordo com o referido autor há inúmeros gêneros textuais, como por exemplo: história em quadrinhos, cardápio do restaurante, bula de remédio, receita, notícia jornalística, bate-papo por computador, etc.

Nesta perspectiva, o professor poderá planejar em suas aulas o uso de diferentes gêneros textuais para desenvolver temas voltados ao Ensino de Ciências, como a utilização de histórias em quadrinhos, as quais poderão ser usadas para introduzir um conteúdo, para gerar discussões ou para finalizar um determinado tema (MARTINS, 2013).

Para Lorenzetti (2000) muitas histórias contadas nos livros de literatura infantil tratam de assuntos referentes à vida das crianças, e a ciência está presente "através dos animais que ilustram as histórias, os ambientes que são apresentados e pelo conteúdo vinculado nestas histórias" (LORENZETTI, 2000, p. 105). Portanto, as histórias podem se tornar disparadores para a realização do trabalho pedagógico, referentes aos diferentes temas, como os seres vivos, a poluição, a problemática do lixo, o corpo humano, a sexualidade, etc.

Outro gênero textual que também contribui para aprendizagem do educando é o informativo, o qual poderá ser discutido no contexto da sala de aula, a fim de buscar informações referentes ao tema estudado.

Lorenzetti (2000) sugere ainda o teatro como outra forma de desenvolver os conteúdos de Ciências, e ressalta que: 
De acordo com Foreman (2010) os estudantes aprendem de formas diferentes, ou seja, não da mesma forma, e com as mesmas estratégias, por isso, é importante que o professor planeje diferentes estratégias didáticas. $E$ complementa que "a pesquisa nos diz que as abordagens ativas de aprendizagem como a dramatização, que envolvem o intelecto de maneiras prazerosas e menos ameaçadoras, devem ter um papel muito mais no Ensino de Ciências do que tiveram no passado" (FOREMAN, 2010, p. 141). A referida autora argumenta que "[...] os estudos indicam que a dramatização, como forma de modelagem física, pode ajudar os alunos a enxergar e a entender conceitos científicos abstratos" (FOREMAN, 2010, p. 141).

As rodas de conversa são comumente utilizadas como estratégia de ensino pelos professores da educação infantil, e têm como objetivo o desenvolvimento da oralidade. Para Alessi (2011, p. 189) essa atividade "[...] contribui para a aprendizagem da escuta, estimula o desenvolvimento da linguagem oral e permite a todos que possam se expressar. É uma estratégia importante que amplia a competência narrativa e as possibilidades discursivas das crianças".

Assim, considera-se que essa prática deve ser também desenvolvida nos anos iniciais do ensino fundamental, prevalecendo as "interações discursivas" (SASSERON, 2013, p. 43) no Ensino de Ciências. Sasseron (2013, p. 43) explica que "é por meio do debate entre os pares que, muitas vezes, os conhecimentos científicos são organizados." Portanto, nas aulas de Ciências, de acordo com a referida autora, é importante que sejam promovidos debates no interior das salas de aula, e que o papel do professor é fundamental para que proponha problemas, faça perguntas, questione os comentários e as informações dos estudantes. Nesse sentido a "resposta dos alunos pode vir em palavras faladas, mas, em alguns casos, na ausência delas, gestos auxiliam na expressão das ideias" (SASSERON, 2012, p. 43).

Essa proposta de atividade não é considerada fácil para o professor, pois há a necessidade de saber ouvir e entender como os estudantes pensam, e o que conhecem sobre determinado tema proposto no ensino de Ciências. O professor precisa estar atento às respostas dos estudantes, para que de fato contribua para ampliação do conhecimento e que gere, portanto, o diálogo, que é necessário para o processo de aprendizagem do estudante.

Outra estratégia de ensino que pode ser bastante rica em aprendizagem para os estudantes são as atividades de campo. Esta proposta "substitui a sala de aula por outro ambiente, natural ou não, onde existam condições para estudar as relações entre os seres vivos ali presentes, incluindo a interação do homem nesse espaço, explorando aspectos naturais, sociais, históricos, culturais, entre outros" (VIVEIRO; DINIZ, 2009, p. 3).

Dessa forma, esse tipo de atividade envolve planejamento, disposição para responder perguntas inesperadas, envolvimento do professor na atividade, a exploração do local, análise dos dados recolhidos na exploração do espaço e a avaliação, ou seja, se realmente os objetivos de aprendizagem foram alcançados (VIVEIRO; DINIZ, 2009). O professor antes de realizar o passeio necessita deixar 
claro aos estudantes o que se pretende com a atividade, a fim de que esta estratégia contribua para a aprendizagem.

A Feira de Ciências também pode ser uma atividade importante para iniciar o processo de alfabetização científica e tecnológica no ensino fundamental. (LORENZETTI, 2000). Lorenzetti (2000) explica que a feira de Ciências possui determinadas etapas para a sua implantação. A primeira refere-se ao planejamento dessa atividade, o qual deverá ser realizado juntamente com os estudantes, "definindo a forma de realização do evento e os possíveis projetos que serão desenvolvidos" (LORENZETTI, 2000, p. 120). Para o autor os projetos desenvolvidos devem estar relacionados com os conteúdos trabalhados ou que estão sendo estudados, bem como com projetos de outros assuntos. Outra etapa destacada por Lorenzetti (2000) é a sistematização do projeto, na qual os estudantes definirão o problema a pesquisar, estabelecerão a justificativa do projeto, os seus objetivos e as alternativas para resolução da questão problema. Contudo, esta etapa pode ser considerada complexa para os alunos dos anos iniciais, devido ao fato da necessidade da sistematização das ideias e de escrevêlas no papel. Mas, com o auxílio do professor os alunos poderão organizar seu projeto de pesquisa.

Depois de realizada a elaboração do projeto os estudantes deverão "sistematizá-lo buscando bibliografias complementares e realizando os experimentos que o trabalho requer" (LORENZETTI, 2000, p. 120). Para o autor esta fase poderá ser mais bem realizada pelos alunos de 4으 e 5o ano. Após a elaboração do problema, os alunos iniciam a etapa de buscar o referencial teórico que orientará a pesquisa. Esse referencial poderá ser composto por: revistas especializadas, pesquisa na internet, entrevistas, livros técnicos, e outros. Depois de concluído o trabalho os estudantes terão a oportunidade de apresentar a pesquisa para o público, apresentando as conclusões que o grupo elaborou. Para Lorenzetti (2000) esta etapa é considerada muito importante, pois os estudantes podem compartilhar ideias com colegas, professores e as pessoas da comunidade, possibilitando construção de conhecimento.

As atividades experimentais contribuem para que o estudante participe ativamente da proposta de ensino apresentada, sendo outro recurso didático que se considera importante de ser planejado pelo professor. Pois segundo Silva e Silva $(2012$, p.7):

Colocar um sujeito em situação de experimentação significa permitir que questione seu conhecimento e o que o objeto do conhecimento quer mostrar. Vemos, assim, um aluno que não se mostra passivo ao seu processo de ensino e aprendizagem, começa a se envolver em tal processo, interagindo com o objetivo de desenvolver seus saberes, buscando compreender o que o fenômeno visto e traçar significados com as estruturas que já obtém.

No entanto, os autores supracitados destacam que a experimentação só terá valor pedagógico se levar a um "desequilíbrio e transformações na estrutura cognitiva do aluno, caso contrário pode se resumir a um passatempo sem significado educacional" (SILVA; SILVA, 2012, p. 7). Rosa, Rosa e Pecatti, (2007, p.265) destacam que: 
Contudo, é necessário rever essa forma como é vista a experimentação, pois o que se espera com esta atividade é que a criança amplie seu conhecimento sobre os fenômenos naturais (ROSA; ROSA; PECATTI, 2007). Portanto, o papel do professor é basilar nesse processo, a fim de desafiar o estudante a buscar a compreensão de algo novo que Ihe é apresentado. Concorda-se com Lorenzetti (2000), que considera que o planejamento do professor é fundamental, pois este deverá saber que objetivos de aprendizagem que se quer alcançar com a atividade de experimentação.

Os vídeos educativos, também, podem ser ricos recursos pedagógicos, no sentido de que os estudantes compreendam os assuntos que estão sendo discutidos na aula de Ciências. Para tanto, Lorenzetti (2000) destaca que é fundamental que o professor analise o filme antes, a fim de destacar os pontos principais para sistematizar os conteúdos que serão desenvolvidos em aula. 0 autor complementa que é essencial que o professor, após o vídeo, realize discussões sobre o tema do filme, "para que os estudantes relatem o que observaram, relacionando fatos e coordenando-os" (LORENZETTI, 2000, p. 112). Além das discussões orais, o professor poderá solicitar registros escritos, que poderão ser através de desenhos ou textos.

O jogo didático, também pode ser considerado um material didático positivo na sala de aula, no entanto, tem que ser algo que seja planejado e controlado. Isto significa que os estudantes precisam estar atentos e concentrados nessa atividade proposta, para que assim, o professor possa alcançar objetivos de aprendizagem. Nessa perspectiva os jogos precisam ser motivadores, divertidos e desafiadores. Para Ward (2012, p. 161) os jogos oferecem oportunidades para os estudantes "aprenderem o conhecimento da ciência e o vocabulário associado de um modo interessante. É possível promover a aquisição da linguagem e o prazer de forma efetiva com o uso de jogos científicos".

Uma questão importante destacada por Ward (2012, p. 170) refere-se à importância de "garantir que o conhecimento aprendido nos jogos seja cientificamente correto, pois os alunos recordarão a atividade e o aprendizado". Por isso é importante o professor conhecer o jogo e avaliá-lo, verificando se este é recomendável para desenvolver o conteúdo esperado.

Outro recurso que poderá ser utilizado pelo professor no ensino de Ciência é o computador. Em relação ao seu uso, Lorenzetti (2000, p. 118) destaca que "espera-se que, com o auxílio do professor os alunos interajam com o computador, construindo conhecimentos" e ressalta que os professores precisam ser capacitados para poderem usar o computador como um recurso pedagógico, e que se percebam como peças chaves para que realizem as intervenções e interações necessárias, para que os estudantes tenham acesso a novos saberes. Outro aspecto apontado pelo referido autor é a importância das escolas serem equipadas com esses recursos com o objetivo de que o estudante tenha acesso a esse tipo de tecnologia.

Bonatto, Silva e Lisboa. (2013) destacam que o gestor pode ser um "facilitador" ou um "dificultador" no processo de articulação da informática com 
a educação, pois, muitas vezes, não se sabe se os computadores que estão na escola serão usados pelos professores no processo de aprendizagem.

A escola, portanto, "[...] não dever negar-se a mudar; pelo contrário, ela deve buscar formas de trazer essas tecnologias - que fazem parte do cotidiano social de grande parte dos alunos - para dentro de seu espaço, de forma a auxiliar o processo de socialização, ensino-aprendizagem e produção de conhecimento" (GOMES, 2011, p. 269).

Porém, não pode desconsiderar o papel do professor neste processo, pois ele é o responsável pelo planejamento das ações educativas realizadas na escola. Pois, o uso adequado do computador dependerá da intencionalidade educativa do professor e do seu conhecimento sobre as possibilidades de uso desse equipamento, para que os alunos tenham aprendizagens relacionadas ao ensino de Ciências.

\section{METODOLOGIA DA PESQUISA}

O gênero da presente investigação é a pesquisa empírica, a qual consiste em um recorte de uma dissertação de mestrado cujo objetivo geral foi o de estudar e analisar as ações educativas desenvolvidas pelos professores que lecionam Ciências no Ciclo II do Ensino Fundamental da rede municipal de Curitiba, a fim de identificar se tais ações contribuem para o processo de alfabetização científica e tecnológica dos estudantes. Os participantes da pesquisa foram nove (9) professores do 4 을 ano e do 5 ㅇ ano, todos do sexo feminino.

Para a seleção dos professores foram considerados dois critérios, sendo que o primeiro se referia a atuar no Ciclo II do Ensino Fundamental e o segundo que os professores deveriam ser de escolas diferentes. Para escolher as escolas participantes da pesquisa, foi definido que seria uma de cada Núcleo Regional de Educação de Curitiba, sendo que neste município há nove (09) núcleos. Após a autorização da Secretaria Municipal de Educação foi feito contato com as diretoras das escolas, via telefone, para verificar o interesse das mesmas em participar da investigação.

Após a autorização da equipe pedagógica, esta definiu, juntamente com o grupo de docentes, o professor do Ciclo II (4ㅇ e 5 o ano), que participaria da pesquisa. Posteriormente a autorização da equipe pedagógico-administrativa e da aceitação do professor em participar da investigação, foi marcada a data para realização da entrevista. No momento da entrevista foram agendadas as observações das aulas e foram solicitadas cópias dos planos de aulas, para posterior análise.

Para a constituição dos dados da pesquisa, foram realizadas entrevistas com nove (9) professores, observações de suas aulas, perfazendo um total de 25 aulas observadas, análise dos planos de aula e das Diretrizes Curriculares para a Educação Municipal de Curitiba (CURITIBA, 2006).

Para a análise dos dados utilizou-se a Análise Textual Discursiva (ATD) de Moraes e Galiazzi (2011). Segundo esses autores "a análise textual discursiva é uma abordagem de análise de dados que transita entre duas formas consagradas de análise na pesquisa qualitativa que são a análise de conteúdos e a análise de discurso" (MORAES; GALIAZZI, 2006, p. 118). Eles argumentam que "a análise 
textual discursiva opera com significados construídos a partir de um conjunto de textos. Os materiais textuais constituem significantes a que o analista precisa atribuir sentidos e significados" (MORAES; GALIAZZI, 2011, p. 13). Sendo esse conjunto de documentos denominado de corpus da pesquisa, que para presente investigação pode ser visto na tabela 1 apresentada a seguir:

\begin{tabular}{c|c}
\multicolumn{2}{c}{ Tabela 1 - Corpus da pesquisa } \\
Corpus da pesquisa & Interlocutores \\
\hline 09 entrevistas com & \\
professores (P1-P9) & o9 professores do Ciclo \\
25 observações de & II do Ensino \\
aulas (AULA1- AULA3) & Fundamental \\
09 planos de aula (PL- & \\
P1 - PL-P9) & \\
\hline $\begin{array}{c}\text { Diretrizes Curriculares } \\
\text { para a Educação }\end{array}$ \\
Municipal de Curitiba \\
(DC) & Documento da esfera \\
& municipal
\end{tabular}

Após definido o corpus, o pesquisador poderá dar início ao ciclo de análise, que possui determinadas etapas, a saber: desconstrução e unitarização dos textos, estabelecimento de relações e categorização, captando o novo emergente e o processo de auto-organização. A desconstrução do texto e unitarização referem-se à análise dos materiais em seus detalhes, dando origem a fragmentação destes, a fim de atingir as unidades constituintes, ou seja, os enunciados do fenômeno estudado.

A partir da unitarização se originam condições para a categorização, com a emergência de novos entendimentos e sentidos. Esta, portanto, é a segunda etapa da ATD, ou seja, o estabelecimento de relações e categorização. As categorias são os conjuntos dos elementos de significação próximos. É no conjunto das categorias que serão constituídos os elementos que darão origem a organização dos metatextos, os quais são explicações das relações entre as categorias (MORAES; GALIAZZI, 2011). Moraes (2003) relata que "os metatextos são constituídos de descrição e interpretação, representando o conjunto um modo de compreensão e teorização dos fenômenos investigados." (MORAES, 2003 , p. 202). Nesse sentido o autor complementa que o pesquisador nesse momento se assume como o "autor de seus argumentos" (MORAES, 2003, p. 202). Esta é a terceira etapa do ciclo de análise, denominado captando o novo emergente. $\mathrm{E}$ a última etapa que se refere ao processo de auto-organização que tem como objetivo a emergência das novas compreensões sobre o fenômeno investigado.

As categorias de análise foram definidas a priori, a partir do referencial teórico. Sendo que neste artigo serão discutidas duas categorias, a saber: Recursos didáticos e Estratégias de ensino, por meio de proposições, conforme proposto pela a ATD. 


\section{RECURSOS DIDÁTICOS}

Proposição I: A maioria dos professores utiliza como recurso didático o computador para acessar a internet e vídeos, além do Datashow, nas aulas de Ciências. As Diretrizes Curriculares para a Educação Municipal de Curitiba, também, destaca o vídeo como um recurso didático que poderá ser utilizado no Ensino de Ciências.

De acordo com as entrevistas realizadas com os professores, constata-se que estes se utilizam de diferentes recursos didáticos e estratégias de ensino para desenvolver os conteúdos propostos. Sendo que o computador para acessar a internet, bem como vídeos aparecem na maioria dos discursos dos professores. 0 recurso didático mais citado foi vídeos. Muitos citaram o laboratório de informática como um espaço bastante utilizado para passar os vídeos e para acessar a internet. Os professores P1, P2, P4, P7 e P9 destacam que se utilizam desse espaço para poderem ter acesso ao computador e utilizarem os jogos e terem acesso a vídeos, como nesses trechos a seguir:

Vamos pensar o que a escola disponibiliza, na escola hoje... quando se trabalha o corpo humano, nós temos o esqueleto, o esquema do corpo humano, microscópio, hoje nós temos acesso a internet [...] Mesmo se vai ser usado vídeos, tem que usar o laboratório de informática, porque na sala nós não conseguimos passar um determinado documentário ou coisa parecida, e daí nós temos que usar o laboratório de informática (P1).

Eu já levei as crianças no laboratório de informática, no caso o Data Show, eu já levei no laboratório para eles jogarem, porque existem muitos jogos voltados ao corpo humano, já levei o Datashow para a sala de aula. Tem o microscópio, a massa de modelar, recorte e colagem, essas coisas também...pesquisa que volte meia, eu mando para casa [...] ...nós também utilizamos a biblioteca para a aula de Ciências... um trabalho sobre gênero, a gente contou toda uma história, dai eles fizeram todo um trabalho com este tema, que até está exposto aqui ao lado. Então a gente procura vários recursos... (P2).

Nós temos a sala de informática, a gente pode agendar aula nesse espaço e eles, também, podem participar da aula de informática, a gente pode acessar os sites, pode fazer atividade através dos sites. Isso chama muito atenção deles, porque eles adoram mexer no computador [...] (P4).

Eu utilizo os livros didáticos, cartazes, laboratório de informática, uso o computado, para jogos, para passar o conteúdo, para ter outra forma de explicar o conteúdo [...] ge gente trabalhava muito a questão do corpo humano, as músicas, como da Xuxa, Cabeça, ombro, joelho e pé, uso televisão com vídeo... vou atrás do vídeo que esteja de acordo com o conteúdo que está sendo trabalhado (P7).

[...] a gente tem bastante opção aqui no colégio, mas a princípio a gente usa muito a vídeo-aula, porque a gente tem bastante, como é que eu vou te falar... tem coisas novas lá, então é mais vídeos, revistas de Ciências que a gente tem na biblioteca, que tem assuntos muito bons também [...] [...] tem o laboratório de informática, que a gente pesquisa, algum site que eles possam entrar e trabalhar junto com a gente (P9). 
Nos planos de aula da maioria dos professores foi possível verificar os vídeos como recurso didático, como nos fragmentos a seguir retirados dos planos dos professores P2 e P4, para exemplificar esta afirmação:

No plano de aula do P2, no período de julho a setembro/2014, verificou-se que 0 professor utilizou os seguintes recursos didáticos: Imagens (representações), livro didático, livro de literatura infantil, vídeo sobre fecundação.

No plano de aula da P4 nos meses de outubro a dezembro/2014, verificou-se que o professor utilizou os seguintes recursos didáticos: Caixa de perguntas, Livro didático, Vídeos (Viagem Fantástica do corpo humano, $\mathrm{O}$ incrível processo do nascimento, Tudo sobre menstruação), Imagens (representações).

Nas aulas observadas constatou-se que os professores P1, P2, P3, P7, P8 e P9 se utilizaram de vídeos para apresentar e desenvolver os temas de Ciências, como evidenciado nos fragmentos das aulas observadas dos professores P1, P2 e P3:

A primeira parte da aula, os estudantes assistiram a um vídeo referente às fases da vida. Primeiro a professora passou o vídeo com o som, isto é, com a fala dos personagens, depois ela tirou o som e pediu para que as crianças refletissem a partir das imagens (AULA 1 - P1).

Depois desse momento de discussão referente à atividade proposta, a professora explicou aos alunos que eles iriam ao laboratório de informática para assistir a um vídeo sobre a fecundação. Este vídeo mostrava o momento da fecundação, a junção do óvulo com o espermatozoide, e o desenvolvimento do bebê no útero materno (AULA 1 - P2).

O primeiro vídeo que as crianças assistiram referia-se ao ciclo menstrual e a ovulação. E o segundo vídeo mostrava o momento da fecundação, junção do espermatozoide com o óvulo e o desenvolvimento do bebê no decorrer dos meses da gestação (AULA 2 - P3).

As Diretrizes Curriculares para a Educação Municipal de Curitiba (2006) destacam que:

Existem muitos recursos didáticos à disposição do professor que podem contribuir para a melhoria do seu trabalho pedagógico, como o livro didático, laboratórios, vídeos, softwares, entre outros. "Fica a critério de o professor selecionar o melhor recurso disponível, conforme sua realidade" (CURITIBA, 2006, p. 19, grifo nosso).

Conclui-se por meio das análises das falas dos professores, dos planos de aula, bem como pelas observações das aulas, que o recurso didático vídeo foi um dos mais utilizados pelos professores, com o objetivo de desenvolver os conteúdos de Ciências. Constata-se que esses momentos eram planejados, pois foram previamente selecionados nos planos de aula, e se compreende que esses vídeos foram vistos e analisados pelos mesmos, a fim de desenvolver determinado conteúdo. Lorenzetti (2000, p. 111) destaca os vídeos educativos como um dos dez princípios didático-pedagógico que poderá contribuir para o desenvolvimento da alfabetização científica dos estudantes nos anos iniciais do ensino fundamental. No entanto, considera que estes devem ser antecipadamente analisados pelo professor, "localizando os pontos de sua 
interferência para sistematizar os conteúdos, para que a aprendizagem significativa ocorra efetivamente".

Foi possível observar durante as aulas dos professores que os vídeos eram vistos pelos estudantes, e depois o professor comentava ou fazia questionamentos aos estudantes a respeito do tema discutido no vídeo, dando ênfase aos conteúdos que já havia sido trabalhado, ou para iniciar um tema novo, como se os vídeos fossem disparadores para desenvolver os conteúdos propostos. Nessa perspectiva, Lorenzetti (2000, p. 112) salienta que o professor após a visualização do vídeo pelos estudantes, deverá proporcionar momentos de discussão em sala de aula a partir do filme, com o objetivo de que os estudantes "relatem o que observaram, relacionando fatos e coordenando-os. Assim, propiciam-se condições para que realizem ligações lógicas, estabelecendo conexões entre ações e reações dos objetos".

É importante destacar que o recurso didático mais usado pelos professores é o vídeo. Mas, nas análises realizadas observou-se a utilização do computador, sendo o uso da sala de informática, também, citado pelos professores. O livro didático também apareceu na análise dos dados, tanto no plano de aula como no momento da observação. Porém, a maioria dos professores apontou que esse recurso era, muitas vezes, limitado e que não contemplava os conteúdos necessários para a turma que atuavam. Ao planejar as aulas, os professores baseavam-se em pesquisas em outros livros didáticos, não o livro didático da turma, ou mediante o uso da internet.

Considera-se importante que o professor ao planejar sua aula, organize diferentes recursos didáticos, não ficando restrito ao quadro de giz ou ao livro didático. $\mathrm{O}$ vídeo poderá ser um recurso que possibilitará o professor ampliar o conhecimento do estudante para determinada temática voltada às Ciências Naturais, contribuindo, dessa forma, para que o estudante tenha contato com a linguagem científica, a qual é necessária para o desenvolvimento da ACT. O vídeo também contribui como disparador para os diálogos que são necessários nos processos de ensino e de aprendizagem. Pois a partir de um vídeo o professor organiza sua fala e possibilita que o estudante também discuta o que entendeu sobre determinado tema apresentado. Observou-se que o vídeo foi utilizado em muitas aulas como disparador para discussão sobre as temáticas de Ciências Naturais em sala de aula.

\section{ESTRATÉGIAS DE ENSINO}

Proposição I: A leitura de diferentes gêneros textuais é a estratégia mais utilizada pelos professores, como meio para buscar informações referentes aos conteúdos relacionados às Ciências Naturais. Bem como a leitura é considerada pelas Diretrizes Curriculares para a Educação Municipal de Curitiba, um procedimento que poderá ser realizado pelo estudante nas aulas de Ciências.

Nas falas dos professores é evidente que os mesmos utilizam a leitura de diferentes gêneros textuais, como o professor P2 que relata que utiliza a Biblioteca nas aulas de Ciência e o professor P1 que trabalha com textos, charges e livros de literatura infantil. $O$ professor P7 relata que desenvolve atividades com o uso da música e o P9 que se utiliza do suporte textual revista para buscar textos voltados à área do conhecimento Ciências, como nos fragmentos a seguir: 
[...] Mesmo se vai ser usado vídeos, tem que usar o laboratório de informática, porque na sala nós não conseguimos passar um determinado documentário ou coisa parecida, e daí nós temos que usar o laboratório de informática. Xerox eu uso bastante, textos, charges, livro de literatura infantil uso pouco (P1).

[...] nós também utilizamos a biblioteca para a aula de Ciências... em um trabalho sobre gênero, a gente contou toda uma história, daí eles fizeram todo um trabalho com este tema, que até está exposto aqui ao lado. Então a gente procura vários recursos... (P2).

Eu utilizo os livros didáticos, os cartazes, também utilizo o laboratório de informática, uso o computador, para jogos, para passar o conteúdo, para ter outra forma de explicar o conteúdo [...]a gente trabalhava muito a questão do corpo humano, as músicas, como da Xuxa, Cabeça, ombro, joelho e pé, uso televisão com vídeo... (P7).

[...] a gente tem bastante opção aqui no colégio, mas a princípio a gente usa muito a vídeo-aula, porque a gente tem bastante, como é que eu vou te falar... Tem coisas novas lá, são mais vídeos, revistas de Ciências que a gente tem na biblioteca que tem assuntos muito bons também [...].

Nos planos de aula constatou-se a leitura de diferentes gêneros textuais como forma de buscar informações sobre os conteúdos de Ciências Naturais. Nos planos de aulas dos professores P1, P2, P3, P4, P5 foi possível encontrar estratégias de leitura de textos informativos, a leitura de livros de literatura infantil, leitura de histórias em quadrinhos, cópia do quadro de textos informativos sobre o tema que estava sendo desenvolvido, fazer leitura do texto e marcar as ideias principais.

Constatou-se nas observações das aulas, que a leitura de textos informativos contribuía para o desenvolvimento das aulas dos professores, pois após a leitura faziam-se as discussões dos temas. Nas aulas foi observada a leitura de diferentes gêneros textuais como estratégia de ensino, como por exemplo: história em quadrinho, poemas, literatura infantil, informativos, o que é corroborado com os trechos das aulas dos professores P1, P2, P3, P4, P5, P7, P9:

[...] a professora deu um texto informativo sobre os hormônios e as mudanças que ocorrem no corpo do indivíduo quando se está na puberdade. Cada criança leu uma parte do texto e a professora fez as explicações sobre o conteúdo (AULA 1 - P1). "A professora iniciou a aula com a leitura de um poema A alegria da Vida" e solicitou que cada criança lesse uma estrofe do texto, e após a leitura realizou a pergunta: Do que está falando o texto? (AULA $1-P 2)$.

Depois da explicação sobre as diferentes maneiras de manifestar a sexualidade, a professora leu um livro chamado Feminina de menina e Masculino de menino da autora Márcia Leite. Neste momento as crianças gostaram muito, participando, dando risadas e opiniões (AULA 1 - P3).

[...] a professora solicitou que as crianças pegassem seus cadernos para copiar o texto da lousa. Após a escrita de uma parte do texto no quadro, a professora o leu em voz alta para as crianças escutarem (AULA 1 - P4). [...] a professora encaminhou os estudantes até a sala de informática para ler uma História em Quadrinhos tinha como tema o solo. (AULA 1 - P5). 
Após a explicação do professor, ele distribui o texto para os alunos, o qual tratava sobre a Superfície da Terra, o qual destacava sobre os oceanos e os continentes, sobre as partes altas e baixas da superfície terrestre, como as montanhas e os vales, os vulcões. O professor pediu que cada estudante lesse um trecho do texto (AULA 2 - P7).

[...] para finalizar a aula ela leu um livro de literatura infantil. Por que quando os meninos são chamados de bicha ficam tão irritados? E o livro explicava que chamar um menino de bicha é a mesma coisa que chamar um menino de homossexual, os homossexuais são pessoas que tem preferência sexual por pessoas do mesmo sexo. O livro relatava sobre a questão do preconceito e a não aceitação das pessoas [...] (AULA 1 - P9).

Após assistirem ao vídeo o professor solicitou que um estudante lesse a história em quadrinhos que estava no livro didático de Ciências, a qual relatava a história de uma menina que estava com amidalite causada por bactérias (AULA $3-P 9)$.

As Diretrizes Curriculares para a Educação Municipal de Curitiba (CURITIBA, 2006) considera a leitura de textos como um procedimento que poderá ser realizado pelos estudantes nas aulas de Ciências como destacado neste trecho: "São procedimentos que possibilitam a aprendizagem significativa: a problematização, a observação, a experimentação, a comparação, o estabelecimento de relações entre fatos e ideias, a leitura e a escrita de textos [...]" (CURITIBA, 2006, p. 17, grifo nosso).

Considera-se que a leitura como estratégia de ensino em Ciências nos anos iniciais contribui para a formação dos estudantes. Corroborando com essa ideia Cagliari (2009, p. 130) aponta que "a atividade fundamental desenvolvida pela escola para a formação dos alunos é a leitura. É muito mais saber ler do que saber escrever. $\mathrm{O}$ melhor que a escola pode oferecer aos alunos deve estar voltado para a leitura". Dessa maneira, compreende-se que as aulas de Ciência precisam se tornar momentos de leitura de diferentes textos, a fim de buscar as informações sobre determinados temas de Ciências trabalhados em sala de aula. Para Sedano (2013) a formação do leitor autônomo não pode ficar restrita a Língua Portuguesa, mas sim que esse é um papel de todas as áreas. $O$ autor considera que por meio da leitura é possível "aumentar e aprofundar conhecimentos sobre determinado campo cultural e científico, ampliar nosso vocabulário pessoal e, em consequência, interferir na reflexão e construção do discurso. (SEDANO, 2013, p. 78)".

A partir da citação de Sedano (2013), avalia-se importante que nas aulas de Ciências os professores leiam diferentes gêneros textuais com os estudantes, com o objetivo de que com a leitura, eles possam desenvolver-se como leitores autônomos, e não apenas como decodificadores de textos; que busquem esclarecer dúvidas por meio da leitura e que desenvolvam um pensamento crítico diante do conhecimento apresentado mediante a leitura. Enfim, que os estudantes sejam leitores que compreendam o que leem, e que se utilizem desses conhecimentos adquiridos na sua prática social. Em relação aos diferentes gêneros textuais, Sedano (2013, p. 80) salienta que "os textos devem abranger uma diversidade de gêneros, pois o contato com uma diversidade de gêneros permite que o aluno conheça diferentes estruturas textuais, amplie seu vocabulário e enriqueça sua produção textual". 
Nos planos de aula e nas aulas observadas constata-se que o texto mais utilizado pelos professores foi o texto informativo como base para o desenvolvimento dos conteúdos. Sendo assim, considera-se que é importante variar os gêneros textuais, para que os estudantes reflitam sobre os diferentes textos que circulam na sociedade e que funções eles possuem na prática social. Como por exemplo: fichas técnicas de animais que trazem informações sobre determinado bicho; receitas que podem ser lidas e discutidas para desenvolver o tema referente à alimentação, bem como o cardápio; rótulos de embalagem, folhetos de mercado, etc.

Nesse sentido, Lorenzetti (2000) destaca como iniciativas didáticometodológicas para o uso de livros de literatura infantil, a revista Ciência Hoje das Crianças, que é considerada um suporte textual, e as paródias, as músicas, sendo que, estes textos poderão contribuir para o desenvolvimento da alfabetização científica dos estudantes.

O trabalho pedagógico voltado para a leitura de texto informativo, ou outros gêneros textuais, contribui para que o estudante se aproxime da linguagem científica, compreendo conceitos importantes que estão relacionados às Ciências Naturais, proporcionado o desenvolvimento da ACT. Mas, ler para responder questionário, talvez não seja o suficiente para que o estudante tenha uma compreensão do texto e realize uma leitura crítica do que lê. É necessário que o professor faça relações daquilo que é lido com questões do cotidiano, que a partir da leitura o professor indague seus estudantes, que os questione, que possibilite que o estudante fale sobre o que compreendeu a partir da leitura, enfim, que o mesmo seja o mediador desse processo. Consideramos que ler textos com autonomia e compreensão sobre assuntos voltados às temáticas que envolvem Ciência e Tecnologia é uma das habilidades que precisam ser desenvolvidas na escola para que se desenvolva a ACT.

Proposição II: A pesquisa é utilizada por alguns professores como uma estratégia de ensino nas aulas de Ciências.

Alguns professores em suas falas destacam a pesquisa como uma estratégia para desenvolver os conteúdos de Ciências, como constatado nos trechos a seguir:

Eu já levei as crianças no laboratório de informática, no caso o Datashow, eu já levei no laboratório para eles jogarem, porque existem muitos jogos voltados ao corpo humano, já levei o Datashow para a sala de aula. Tem o microscópio, a massa de modelar, recorte e colagem, essas coisas também... pesquisa que volta e meia, eu mando para casa [...] (P2).

Eu uso os meus livros didáticos, os meus que eu tenho uma coleção, porque o livro da turma não dá certo, a internet uso muito, muito, muito..., pesquisa para casa, mas, muitos não têm internet, e às vezes, eles vão ao Farol do Saber que tem aqui, eu uso a revista Ciência Hoje, eu também tenho uma coleção, depende o conteúdo eu pego, e às vezes eu dou para eles ler então agora o tema é sistema solar, eu tenho um monte, então eles leem e a gente discute[...] ( P6).

[...] tem o laboratório de informática, que a gente pesquisa algum site que eles possam entrar e trabalhar junto com a gente (P9).

Na maioria dos planos de aula analisados identificou-se a pesquisa como uma estratégia de ensino utilizada, pois esta palavra "pesquisa" foi citada nestes 
planos. Nas aulas observadas, os professores solicitaram aos estudantes a realização de pesquisa, como tarefa de casa. Desses professores, apenas um requereu que a pesquisa fosse realizada em sala de aula, como observado nestes fragmentos:

A professora explicou para os alunos que havia encontrado um site da Universidade de São Paulo (UNIVESP) que trazia informações sobre o sistema reprodutor feminino e masculino. A segunda parte da aula foi realizar a pesquisa nesse endereço eletrônico, para depois realizar a atividade de revisão proposta pela docente (AULA $1-P 1$ ).

Após os estudantes copiarem no caderno as questões para a pesquisa o professor encaminhou os estudantes ao laboratório de informática. O professor explicou os procedimentos de uma pesquisa falando: São três pesquisas que vocês irão fazer, vocês vão colocar o título, leva um lápis de cor e coloca, gente pesquisa é assim, vocês entram lá no Google, digitam e vai aparecer as páginas. Depois clica lá abre o que está aparecendo, vocês vão ler o que é interessante, não vão copiando tudo. (AULA 3 - P6).

Um pouco antes da finalização da aula o professor escreveu no quadro uma atividade para casa referente à pesquisa sobre os vulcões em atividade no Planeta Terra e para os estudantes desenharem um vulcão. (AULA 2 - P7).

[...] a professora perguntou aos estudantes quem havia feito a pesquisa sobre AIDS que era a tarefa de casa. [...] A docente teve que interromper e falou que depois eles continuavam a conversa, mas que naquele momento seria feita a leitura da tarefa de casa (pesquisa sobre a AIDS). A professora pediu para que quatro crianças lessem sobre o tema pesquisado, e perguntou em que local haviam feito a pesquisa, e eles relataram que tinham feito na internet (AULA 2 P9).

Mediante as análises das falas dos professores, dos planos de aulas, bem como das observações das aulas, constata-se que há um interesse por parte dos professores em planejar a pesquisa como um meio para compreender os conteúdos propostos. No entanto, a maioria das pesquisas foi solicitada para ser feita como tarefas de casa, considera-se que a pesquisa pode e deve ocorrer na sala de aula, tendo o professor como mediador desse processo de aprendizagem. Pois, ao desenvolver esse tipo de atividade na sala de aula, o professor poderá contribuir para que os estudantes desenvolvam e compreendam importantes procedimentos para a realização dessa atividade. Assim, o professor estará articulando o conteúdo conceitual com o procedimental, como sugerido pelos Parâmetros Curriculares Nacionais: Ciências Naturais (BRASIL, 1997).

Considera-se que quando o professor planeja este tipo de atividade deveria oportunizar ao estudante à busca pelo conhecimento, ou seja, a partir de uma questão problema investigar as possíveis respostas para a resolução da pesquisa. Pois "os alunos também precisam ser incentivados a sugerir soluções e respostas para suas próprias questões" (RODEN, 2010, p. 67), bem como para aquelas questões que são decorrentes dos conteúdos propostos.

Nesse sentido, avalia-se que a investigação científica seja importante de ser incentivada e realizada no contexto escolar, iniciando esse processo, desde os anos iniciais do Ensino Fundamental. Por isso compreende-se a pesquisa como uma estratégia importante para que os estudantes compreendam os conceitos 
científicos, e que desenvolvam o processo de ACT. Por isso defende-se que esses momentos de investigação devem acontecer também em sala de aula, sendo o professor o mediador desse processo. Pois de acordo com Sasseron (2013, p. 42) "o mais importante da investigação não é o seu fim, mas o caminho trilhado".

Assim, a investigação poderá contribuir para que os estudantes se interajam e compartilhem ideias em relação ao problema a ser investigado. Para Sasseron $(2013$, p. 43) "em uma investigação, diversas interações ocorrem simultaneamente: interações entre pessoas, interações entre pessoas e conhecimentos prévios, interações entre pessoas e objetos. Todas são importantes, pois são elas que trazem as condições para o desenvolvimento do trabalho". E também para a produção dos conhecimentos em Ciências Naturais.

A estratégia de pesquisa poderá estar atrelada aos recursos didáticos vídeo e o uso das tecnologias da informação, pois os estudantes poderão se utilizar desses recursos para buscarem conhecimentos relacionados às diferentes temáticas desenvolvidas em sala de aula. Mas, para que isso seja possivel é importante que o professor incentive e use esses diferentes recursos e oriente os estudantes a buscarem informações, dados, a partir desses materiais didáticos. Pois, saber investigar e buscar as informações sobre diversos temas são habilidades muito importantes para que o estudante desenvolva a ACT.

Proposição III: A maioria dos professores utiliza a roda de conversa, o diálogo para iniciar as discussões sobre um determinado tema.

A partir das falas da maioria dos professores, constatou-se que esses possuem como objetivo conhecer o conhecimento prévio dos estudantes, a fim de iniciar novos conteúdos. Esta afirmação pode ser verificada nestes trechos dos professores P1, P2, P3, P6, P8 e P9:

Eu sempre tento começar o conteúdo, qualquer conteúdo, partindo do que o aluno conhece, o que ele entende, o que ele percebe. (P1).

Parto da vivência, da experiência dele, como que ele entende, no senso comum, para ocorrer a construção do conhecimento [...] (P1)

Quando é conteúdo novo, que nem agora que é o sistema reprodutor, nós fizemos uma folha... cada um recebeu uma folha para colocar uma curiosidade, sobre o tema e não precisaria se identificar. E ao final fomos lendo as perguntas, quem sabia responder respondia, as que foram possíveis eu também respondi (P2).

O objetivo é estarmos ensinando a criança, a criança está aprendendo, a criança está se aprofundando, trabalhar com as experiências que as crianças trazem de casa, com aquilo que ela já sabe aprofundar nisso e usar isso nas aulas (P3).

Primeiro vejo uma curiosidade, eu sempre gosto de fazer um bate papo antes... (P6).

Eu agora gosto de fazer, às vezes, algum jogo, se não roda de conversa, para poder colher as informações deles primeiro, para depois eu poder começar com o assunto [...] (P8).

A princípio eu tento fazer como se fosse uma roda de conversa entende, levantar algum questionamento para ver até onde eles entendem sobre aquele assunto [...] Eu acho que é muito importante você fazer um... como é que eu vou 
falar... Primeiro ver um todo deles até onde vai o conhecimento, para depois você saber exatamente onde você entra (P9).

Em cinco planos de aula (P3, P5, P6, P7 e P9) foi possível encontrar alguns termos que tem relação com a ideia de conversa sobre o tema proposto, como as palavras discussões e questionamentos, o que sugere um trabalho voltado para a roda de conversa ou conversa em sala de aula.

A partir das observações realizadas das aulas, verifica-se que as crianças possuem liberdade de exprimir suas ideias referentes aos temas, e que grande parte dos professores apresenta-se dispostos a escutá-las, a fim de contribuir para o entendimento relacionado aos temas de Ciências Naturais. Em algumas turmas verificou-se que os estudantes gostam muito de falar sobre temas de seu cotidiano, e que são muito questionadores diante do conhecimento. Isto significa dizer que realizam muitas perguntas sobre os conteúdos propostos pelos docentes. Para Ward e Roden (2010, p. 37) os alunos devem se incentivados a realizarem perguntas, a fim a ampliarem os conhecimentos sobre o mundo que os rodeia. E ainda as autoras consideram esse momento, importante para que os estudantes, mobilizados pelo professor, possam investigar sobre questões das Ciências Naturais. "O questionamento, juntamente com a observação e a investigação, é um aspecto fundamental do desenvolvimento da compreensão dos alunos sobre o mundo".

A partir de fragmentos das aulas observadas constatou-se que os professores lançam questões para os estudantes responderem, e para que estes se sintam interessados pelo conteúdo proposto, gerando dessa maneira a participação dos estudantes nas discussões, nas quais eles dão opiniões e fazem perguntas sobre o conteúdo, como observado nos trechos a seguir:

Após as explicações a professora iniciou a dinâmica, algumas perguntas foram: Meu corpo está diferente, o que está acontecendo comigo? $O$ que é puberdade? $O$ que masturbação? $O$ que são mamilos? Conhecer, ficar $e$ namorar... Será que já está na hora? Por que as mulheres menstruam? O que é menarca? O que é ciclo menstrual? O que é ovulação? O que é polução noturna? Durante o momento das perguntas as crianças participavam tentando responder as questões [...] (Aula 2-P1).

Para realizar a correção ela retomou o texto, fazendo a leitura novamente das estrofes, para verificar a resposta correta. Na última questão, referente à opinião das crianças, estas participaram falando suas respostas, no entanto, a professora teve que fazer várias interferências e voltar ao texto, para que os estudantes pudessem compreender o sentido da última estrofe do poema. Dessa maneira a professora escutou as opiniões de cada criança (Aula 1-P2).

A professora iniciou a aula explicando que existem no mundo pessoas que são chamadas de heterossexuais. E perguntou para as crianças: $O$ que são heterossexuais? (Aula 1-P3).

Perguntou para as crianças "Quem aqui que nasceu... quem sabe se nasceu de parto normal ou cesárea?" Neste momento várias crianças começaram a falar ao mesmo tempo, e por causa disso a professora pediu para que levantassem a mão quem nasceu de parto normal (Aula 1 - P4).

Cada trecho era escrito no quadro e a professora explicava o conteúdo, neste momento as crianças tinham a oportunidade de realizarem comentários e 
perguntas referentes ao tema, ou contar fatos de sua vida relacionados ao conteúdo (Aula 2 - P4).

Durante a leitura da história em quadrinhos, a professora, parava em alguns trechos explicava o conteúdo e fazia perguntas para as crianças responderem, o que eles achavam de um determinado trecho do texto (Aula 1 - P5).

Portanto, a partir das análises das falas dos professores, dos planos de aulas e das observações, constatou-se que há uma preocupação por parte dos professores em saber o que as crianças sabem sobre o tema, ou seja, os conhecimentos prevalentes (DELIZOICOV; ANGOTTI; PERNAMBUCO, 2011). Para que depois estes conhecimentos sejam compreendidos mediante a linguagem científica. Assim, uma das estratégias utilizadas para verificar o que os estudantes sabem sobre o conteúdo, é a conversa ou roda de conversa. Nesse processo dialógico o professor também conhece e considera o que os estudantes trazem de conhecimentos para dentro da sala de aula, valorizando dessa forma diferentes saberes, pois de acordo com Freire (1996) "ensinar exige respeito aos saberes dos educandos". E quando o professor considera as falas infantis, no sentido de escutar e compreender, ele estará contribuindo para essa valorização, bem como considerando o estudante não como uma folha em branco, mas sim alguém que tem explicações sobre diferentes fenômenos e fatos que estão presentes no contexto social e natural (DELIZOICOV; ANGOTTI; PERANAMBUCO, 2011).

Nesse sentido acredita-se que por meio de aulas nas quais o professor é o mediador desse processo dialógico, ele contribuirá para o desenvolvimento da oralidade, prática fundamental de ser desenvolvida nos anos iniciais do Ensino Fundamental, bem como para a compreensão da linguagem científica, sendo essa uma etapa importante para o processo de ACT. Compreender o que o estudante conhece sobre determinada temática, é fundamental para o processo de ACT, pois, será a partir desse ponto que o professor organizará e conduzirá sua prática. Percebendo o que seus estudantes já sabem e o que precisa ser ampliado ou ressignificado a partir da linguagem científica.

\section{CONSIDERAÇÕES FINAIS}

A presente investigação teve como propósito identificar se as ações educativas desenvolvidas pelos professores de Ciências Naturais do Ciclo II do Ensino Fundamental contribuem para o processo de ACT. Sendo que essas ações educativas referem-se às estratégias de ensino e aos recursos didáticos planejados para o desenvolvimento dos conteúdos deste componente curricular.

Em relação aos recursos didáticos, concluí-se, por meio das análises dos discursos dos professores, mediante os planos de aula, bem como a partir das observações das aulas, que o recurso mais utilizado é o vídeo, o qual tem como objetivo contribuir para o desenvolvimento dos conteúdos propostos. Importante ressaltar que os momentos de assistir aos vídeos, eram previamente planejados, pois este recurso era citado no plano de aula dos professores. O vídeo poderá ser um recurso importante para o professor, no sentido, de aproximar os estudantes de conceitos científicos e da linguagem científica, o que é essencial para o desenvolvimento da ACT. No entanto, a forma que o professor irá conduzir a aula, a partir desse recurso, é que será o diferencial. 
O livro didático, também apareceu na investigação, no entanto, destaca-se que das vinte e cinco aulas observadas, em apenas quatro aulas foi possível identificar o uso do livro didático pelos professores, reforçando a ideia de que esse não é o recurso mais utilizado pelos professores investigados.

Em relação às estratégias de ensino, destaca-se a pesquisa, a leitura de diferentes gêneros textuais e a roda de conversa como atividades desenvolvidas pelos professores no Ensino de Ciências. Na maioria dos planos de aula identificou-se a palavra pesquisa, como uma forma de encaminhamento metodológico. Assim, constata-se que há um interesse dos professores em planejar a pesquisa para as crianças buscarem informações sobre os conteúdos trabalhados em aula. Entretanto, as pesquisas foram solicitadas pelos professores para serem feitas como tarefa de casa, e não na sala de aula, tendo o professor como mediador desse processo de aprendizagem. Considera-se que essa atividade ao ser realizada em sala de aula contribui para que os estudantes desenvolvam e compreendam importantes procedimentos para a realização desse tipo de proposta de atividade. Compreende-se que pensar, investigar, comparar, classificar, criticar são habilidades importantes para o desenvolvimento da ACT, e que no Ensino de Ciências estas precisam ser trabalhadas e a pesquisa poderá ser uma estratégia importante para o desenvolvimento dessas habilidades.

A roda de conversa também foi uma estratégia relatada nas falas dos professores, como um meio para buscar os conhecimentos prévios dos estudantes. A partir das observações das aulas constatou-se que os estudantes possuem liberdade de exprimir suas ideias e opiniões sobre os temas desenvolvidos nas aulas de Ciências. Nesse sentido, as aulas se mostraram como espaços ricos para as discussões sobre os temas propostos, o que caracterizou uma aula mais dinâmica, na qual os estudantes não se mostraram passivos diante do conhecimento apresentado. Compreender o que o estudante conhece sobre determinado tema é fundamental para que o professor reorganize e replaneje sua prática pedagógica, a fim de ampliar os conhecimentos dos estudantes. Considera-se importante para o desenvolvimento da ACT que o professor respeite os conhecimentos prévios dos estudantes e os considere na prática pedagógica nas aulas de Ciências Naturais.

Entretanto, é importante ressaltar que algumas ações ainda precisam ser realizadas no contexto da escola, verificou-se que há algumas lacunas que precisam ser preenchidas, a fim de atingir o objetivo de desenvolver a ACT nessa etapa de escolarização. As estratégias que pouco apareceram na presente investigação foram: saídas a campo, as Feiras de Ciências, as atividades experimentais; e em relação aos recursos didáticos foram os jogos e brincadeiras.

Em síntese, compreende-se que existem outras estratégias de ensino e outros recursos didáticos que podem ser utilizados no ensino de Ciência. No entanto, considera-se que esses destacados pelos professores sejam relevantes para que o professor desenvolva uma prática pedagógica voltada para a ACT dos estudantes. Contudo, avalia-se que para formação integral do estudante, para uma formação para a cidadania, é indispensável que as estratégias de ensino e os recursos didáticos estejam atrelados a uma metodologia que mobilize o estudante a pensar, a refletir, a argumentar e a questionar. Habilidades consideradas essenciais para que o estudante desenvolva o processo de alfabetização científica e tecnológica nos anos iniciais. 


\title{
The teacher and his educative actions in the scientific and technological alphabetization process in the science teaching on early years of elementary school
}

\begin{abstract}
The aim of this research was to analyse the educative actions developed by the Science teachers from the Cycle II of Elementary School in Curitiba, in order to identify if such actions contribute to the Scientific and Technological Alphabetization process of the students. The present work is a clipping of a master research, with a qualitative approach, and which data were constituted through interviews with nine teachers, class observations, analysis of curricular guideliness to the Municipal Education of Curitiba and analysis of the teacher's class plans. It was utilized the Textual Discursive Analysis by Moraes e Galiazzi (2011), to the data analysis. In this paper is discussed two categories of analysis: Didatic resource and Teaching Strategies. With this study it was possible to identify that the teachers utilize in their classes many different didactic resources and teaching strategies, which is considered relevant to the scientific and technological alphabetization.
\end{abstract}

KEYWORDS: Scientific and technological alphabetization. Early years. Science teaching. 


\section{REFERÊNCIAS}

ABIB, M. L. V. dos S. Por que os objetos flutuam? Três versões de diálogos entre as explicações das crianças e as explicações científicas. In: CARVALHO, Anna Maria Pessoa de. (org.) Ensino de Ciências por investigação. São Paulo: Cengage Learning, 2013, p.93-110.

ALESSI, V. M. Rodas de conversa na educação infantil: as vozes infantis em uma análise Bakhtiniana. Atos de pesquisa em educação - PPGE/ME FURB, V.6, n.1, p. 188-206, 2011.

BONATTO, F. R. de O.; SILVA, A. F.; LISBOA, P. Tecnologias nas atividades escolares: perspectivas e desafios. In: VALE, L. E. L. R. do. MATTOS, M. J. V. M. de. COSTA, J. W. da. Educação digital:a tecnologia a favor da inclusão. Porto Alegre: Penso, 2013.

BORGES, G. L. de. A. Caderno de formação: formação de professores didática dos conteúdos. São Paulo: Cultura Acadêmica, 2012.

BRASIL. Secretaria de Educação Fundamental. Parâmetros Curriculares Nacionais: Ciências Naturais. Secretaria de Educação Fundamental. Brasília, MEC/SEF, 1997.

CAGLIARI, L. C. Alfabetização e linguística. São Paulo: Scipione, 2009.

CRUZ, S. de S., ZYLBERSZTAJN, A. O enfoque ciência, tecnologia e sociedade e a aprendizagem centrada em eventos. In: PIETROCOLA, M. Ensino de Física: conteúdo, metodologia e epistemologia numa educação integradora. Florianópolis: Editora da UFSC, 2001, p.171-196.

CURITIBA. Secretaria Municipal de Educação. Prefeitura Municipal de Curitiba. Diretrizes Curriculares para a educação de Curitiba. V. 3. Ensino Fundamental. Curitiba. 2006.

DELIZOICOV, D.; ANGOTTI, J. A.; PERNAMBUCO, M. M. Ensino de ciências: fundamentos e métodos. 3 ed. São Paulo: Cortez, 2011.

FOREMAN, J. O uso da dramatização para estimular e desenvolver a compreensão dos alunos sobre conceitos científicos. In: WARD, H.; RODEN, J.; HEWLETT, C.; FOREMAN, J. Ensino de Ciências. Porto Alegre: Artmed, 2010, p. 139-160. 
FREIRE, P. Pedagogia da Autonomia: saberes necessários à prática educativa. São Paulo: Paz e Terra, 1996.

GOMES, Elaine Messias. Uma experiência com o uso da Lousa Digital Interativa por profissionais da educação infantil. ETD - Educação Temática Digital, Campinas, V.12, n.esp., p. 268-286, 2011.

HAZEN, R. M., TREFIL, J.. Saber Ciência: do Big Bang à engenharia genética as bases para entender o muno atual e o que virá depois. São Paulo: Cultura Editores Associados, 1995.

LIMA, E. C. A. S. de. A Utilização Do Jogo Na Pré- Escola. Série ideias. n. 10, São Paulo: FDE, p. 24-29, 1992. Disponível em: <http:// www.crmariocovas.sp.gov.br/top. php?=004>. Acesso em: 04/12/2014.

LIMA, E. C. de C.; MAUÉS, E. Uma releitura do papel da professora das séries iniciais no desenvolvimento e aprendizagem de ciências das crianças. Ensaio: Pesquisa em educação em Ciências. V. 8, n. 2, p. 161-175, 2008. Disponível em: $<$ http://www.portal.fae.ufmg.br/seer/index.php/ensaio/article/view/115/166> Acesso em: 27/08/2014.

LORENZETTI, L. Alfabetização Científica no contexto das séries iniciais. 2000. Dissertação. (Mestrado em Educação). Universidade Federal de Santa Catarina, 2000.

MARCUSCHI, L. A. Gêneros textuais: definições e funcionalidade. In: Dionísio, A. P. et al. (org.). Gêneros textuais e ensino. Rio de Janeiro: Lucena, 2002, p. 19-36.

MARTINS, E. K. Histórias em quadrinhos no ensino de Ciências: uma experiência para o ensino do sistema nervoso. 2013. Dissertação (Mestrado em Ensino de Ciências e Tecnologia). Programa de Pós-Graduação em Ensino de Ciências e Tecnologia. UTFPR. Ponta Grossa, 2013.

MORAES, R. Uma tempestade de Luz: a compreensão possibilitada pela análise textual discursiva. Ciência \& Educação, V. 9, n.2, p.191-211, 2003.

MORAES, R., GALIAZZI, M. do C. Análise Textual Discursiva: Processo reconstrutivo de múltiplas faces. Ciência \& Educação, v. 12, n.1, p.117-128, 2006.

MORAES, R., GALIAZZI, M. do C. Análise Textual Discursiva. Ijuí: Ed. Unijuí, 2011. 
RODEN, J.; WARD, O que é Ciência? In: WARD, H.; RODEN, J.; HEWLETT, C.; FOREMAN, J. Ensino de Ciências. Porto Alegre: Artmed, 2010, p. 13-33.

FABRI, F.. O ensino de Ciências nos anos iniciais do ensino fundamental sob a ótica CTS: uma proposta de trabalho dos artefatos tecnológicos que norteiam o cotidiano dos alunos. Dissertação. 2012. (Mestrado em Ensino de Ciências e Tecnologia). Universidade Tecnológica Federal do Paraná, Campus Ponta Grossa. Ponta Grossa, 2012.

RODEN, J. Observação, mensuração e classificação. In: WARD, H.; RODEN, J.; HEWLETT, C.; FOREMAN, J. Ensino de Ciências. Porto Alegre: Artmed, 2010, p.5265.

ROSA, C. W. da., ROSA, A. B., PECATTI, C. Atividades experimentais nas séries iniciais: relato de uma investigação. Revista Electrónica de Enseñanza de la Ciencias. V. 6, n. 2, p.263-274, 2007. Disponível em:

<http://reec.uvigo.es/volumenes/volumen6/ART3 Vol6 N2.pdf> Acesso em: 29/12/2014.

SASSERON, L. H.; CARVALHO, A. M. P.. Almejando a alfabetização científica no ensino fundamental: a proposição de indicadores do processo. Investigações em Ciências, V.13 (3), p. 333 - 352, 2008.

SASSERON, L. H.. Alfabetização Científica no Ensino Fundamental: Estrutura e indicadores deste processo em sala de aula. 2008. Tese (Doutorado em Educação). Faculdade de Educação da Universidade de São Paulo. 2008.

SASSERON, L. H. Interações discursivas e investigação em sala de aula: o papel do professor. In: CARVALHO, A. M. P. de. (org.) Ensino de Ciências por investigação. São Paulo: Cengage Learning, 2013, p.41-61.

SEDANO, L. Ciência e leitura: um encontro possível. In: CARVALHO, Anna Maria Pessoa de. (org.) Ensino de Ciências por investigação. São Paulo: Cengage Learning, 2013, p.77-99.

SILVA, G. R., SILVA, J. A. da. História da Ciência e experimentação: perspectiva de uma abordagem para os anos iniciais do ensino fundamental. In: SEMINÁRIO DE PESQUISA EM EDUCAÇÃO DA REGIÃO SUL. 9., 2012. Anais... Caxias do Sul: UCS, 2012, p. 1-17. 
fundamental. Atos de pesquisa em educação- PPGE/ME. V.07, n.3, p. 853-876, 2012.

VIECHINESKI, J. Sequência didática para o ensino de Ciências nos anos iniciais: subsídios teórico-práticos para a iniciação à alfabetização científica. 2013. Dissertação (Mestrado em Ensino de Ciências e Tecnologia). Universidade Tecnológica Federal do Paraná. Ponta Grossa. 2013.

VIVEIRO, A. A., DINIZ, R. E. da S. Atividades de campo no ensino das ciências e na educação ambiental: refletindo sobre as potencialidades desta estratégia na prática escolar. Ciência em Tela. V. 2 . n. 1, p. 1-12, 2009. Disponível em:<http://www.cienciaemtela.nutes.ufrj.br/artigos/0109viveiro.pdf $>$ Acesso em: 28/12/2014.

INFORSATO, E. do C.; SANTOS, R. A. dos. A preparação das aulas. In: Caderno de Formação: formação de professores. São Paulo: Cultura Acadêmica, 2011, p. 8698.

WARD, H.; RODEN, J. As habilidades que os alunos devem ter para aprender ciência: habilidades processuais. In: WARD, H.; RODEN, J.; HEWLETT, C.; FOREMAN, J. Ensino de Ciências. Porto Alegre: Artmed, 2010, p. 34-51.

WARD, H. A ciência dos jogos. In: WARD, H.; RODEN, J.; HEWLETT, C.; FOREMAN, J. Ensino de Ciências. Porto Alegre: Artmed, 2010, p.161-174. 
Recebido: 2017-07-17

Aprovado: 2018-03-08

DOI: $10.3895 /$ rbect.v11n3.6711

Como citar: BONFIM, H. C. C.; GUIMARÃES, O. M. O professor e suas ações educativas no processo de ACT no ensino de ciências nos anos iniciais do ensino fundamental. Revista Brasileira de Ensino de Ciência e Tecnologia, v. 11, n. 3, 2018. Disponível em: <https://periodicos.utfpr.edu.br/rbect/article/view/6711>. Acesso em: xxx.

Correspondência: Orliney Maciel Guimarães - orliney@quimica.ufpr.br

Direito autoral: Este artigo está licenciado sob os termos da Licença Creative Commons-Atribuição 4.0 Internacional. 